\title{
CONTRIBUCIÓN A LA GEOLOGÍA Y GEOMORFOLOGÍA DE UNA PARTE DEL CANTÓN DE CORONADO; COSTA RICA
}

\author{
Asdrúbal Vargas Sanabria \\ Escuela Centroamericana de Geología, \\ Apdo. 2-14, 2060 Universidad de Costa Rica \\ E-Mail: avargas@ cariari.ucr.ac.cr
}

(Recibido 9/4/1999; Aceptado 10/1/2000)

\begin{abstract}
The geology of the area is defined by basaltic and andesitic lava flows, mud flows, tuffs, alluvium deposits and ash. The basaltic lavas are correlated with the Aguacate Group and the andesitic lavas with the Irazú volcano. The geomorfological features of the río Virilla microbasin indicate that it has a recent development with more channels per square kilometer. The río Durazno microbasin is very narrow and the path of the water to the exit is longer. The geomorphology is composed of six units and there are two main units, one of transition $\left(5-21^{\circ}\right)$ or high slope $\left(15^{\circ}-35^{\circ}\right)$. The regulation plan of management for the Coronado county must consider information upon geology, geomorphology, and natural hazard. This work is neccesary for the implementation of a geografical information system and to improve the soil use management.
\end{abstract}

RESUMEN: La geología está constituida por lavas de tipo basáltico y andesítico, lahares, tobas, aluviones y cenizas. A partir del análisis petrográfico de las unidades de lavas se establecieron correlaciones con las rocas del Grupo Aguacate y con las rocas del volcán Irazú. Las características geomorfométricas de la subcuenca del río Virilla permiten señalar que esta subcuenca está mejor drenada, es más achatada, presenta un estado de desarrollo juvenil y un mayor número de canales por kilómetro cuadrado, mientras que la subcuenca del río Durazno es más estrecha, más elongada y el recorrido del agua hasta el punto final es mayor. La geomorfología comprende seis unidades geomórficas, de las cuales la de pendiente alta $\left(15^{\circ}-35^{\circ}\right)$ y de transición $\left(5^{\circ}-12^{\circ}\right)$ ocupan el mayor porcentaje de área. El plan regulador para el cantón de Coronado debe ser mejorado incluyendo aspectos geológicos, geomorfológicos y geomorfométricos así como amenazas naturales. Este trabajo es básico para la implementación de sistemas de información geográfica, así como para mejorar la planificación del uso del suelo en el área.

\section{INTRODUCCIÓN}

La zona de estudio se ubica al NE del Valle Central, en la falda NW del Macizo Volcánico Irazú y comprende las cuencas hidrográficas del río Virilla y río Durazno, definidas hasta su confluencia y comprendidas en las hojas topográficas Abra \# 3345 I e Istarú 3445 IV (Fig. 1). Los objetivos de este trabajo involucraron, definir la geología y geomorfología de una parte del cantón Vázquez de Coronado, para posteriormente proponer un plan de protección ambiental de esta zona, la cual es considerada como área de recarga para acuíferos profundos del Valle Central. Varios autores han estudiado la geología y petrografía del área de manera regional, entre otros, Krushensky (1972); Tournon (1983); Denyer \& Arias (1990); Denyer, \& Arias (1991); Kussmaul \& Sprechmann (1984); Denyer et al. (1994); Kussmaul (1994). La metodología de trabajo ha involucrado la recopilación de información bibliográfica, cartografiado de las unidades geológicas y geomorfológicas en el campo, análisis de secciones delgadas de roca y fotointerpretación.

La zona de estudio se caracteriza por una precipitación y una temperatura promedio anual de $2000 \mathrm{~mm}$ y $16{ }^{\circ} \mathrm{C}$, respectivamente. En esta región se dió en los últimos años un incremento del desarrollo urbanístico mal planificado sin tener en 

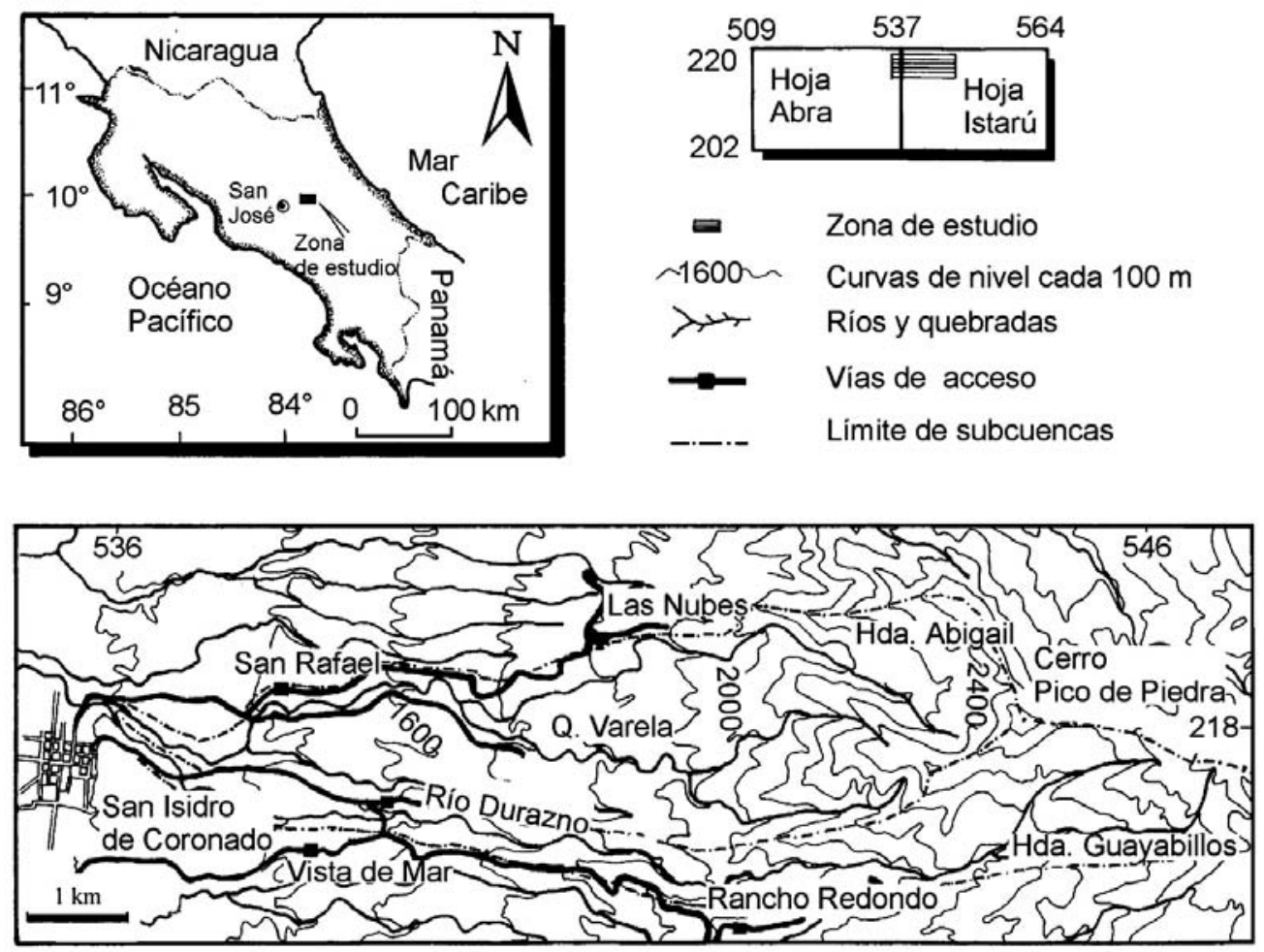

Fig. 1: Ubicación del área de estudio.

cuenta las condiciones geológicas, geomorfológicas, hidrogeológicas, uso del suelo y de protección ambiental. Es por este motivo que la Compañía Nacional de Fueza y Luz ha implementado un Plan de Mejoramiento Ambiental (PLAMA VIRILLA), dentro del cual se pretende aplicar un sistema de información geográfica, para lo cual es fundamental investigar la geología y geomorfología entre otros aspectos.

\section{GEOLOGÍA}

La geología en las subcuencas se ha dividido en cinco unidades (Figs. 2 y 3):

\section{Unidad de vulcanitas río Virilla}

Esta unidad está compuesta por lavas, tobas y lapilli y aflora en el río Virilla a la altura de 2000 m.s.n.m en la hacienda Abigail, en el río Durazno y en las quebradas Varela y Sangrino. Macroscópicamente las rocas son de color gris claro a morado, de textura porfirítica o vesicular, con fenocristales de piroxeno y plagioclasa. Microscópicamente las lavas son basaltos porfiríticos y en ocaciones amigdaloideos. Los minerales esenciales son la plagioclasa (18-36\%) con tamaño máximo de 2,5 x 1,8 $\mathrm{mm}$, augita titanífera $(1,5-16,5 \%)$ con un tamaño máximo de 4,5 mm, olivino (2,5-6,0\%) y magnetita $(1,0-2,5 \%)$. El olivino se presenta frecuentemente como fantasmas completamente alterado a calcita y óxidos de hierro. Otros minerales de alteración son nontronita, clorita y calcita rellenando amigdalas. La mesostasa ocupa entre un 43 a un $66 \%$ de la roca (Cuadro 1), es de tipo intergranular o hialopilítica y está compuesta por plagioclasa, augita, magnetita y ocacionalmente vidrio de color pardo.

En la quebrada Varela se identificaron dos flujos de lava, diferenciados por el contenido de fenocristales de piroxeno, y las texturas vacuolar y porfirítica, separados por una brecha 


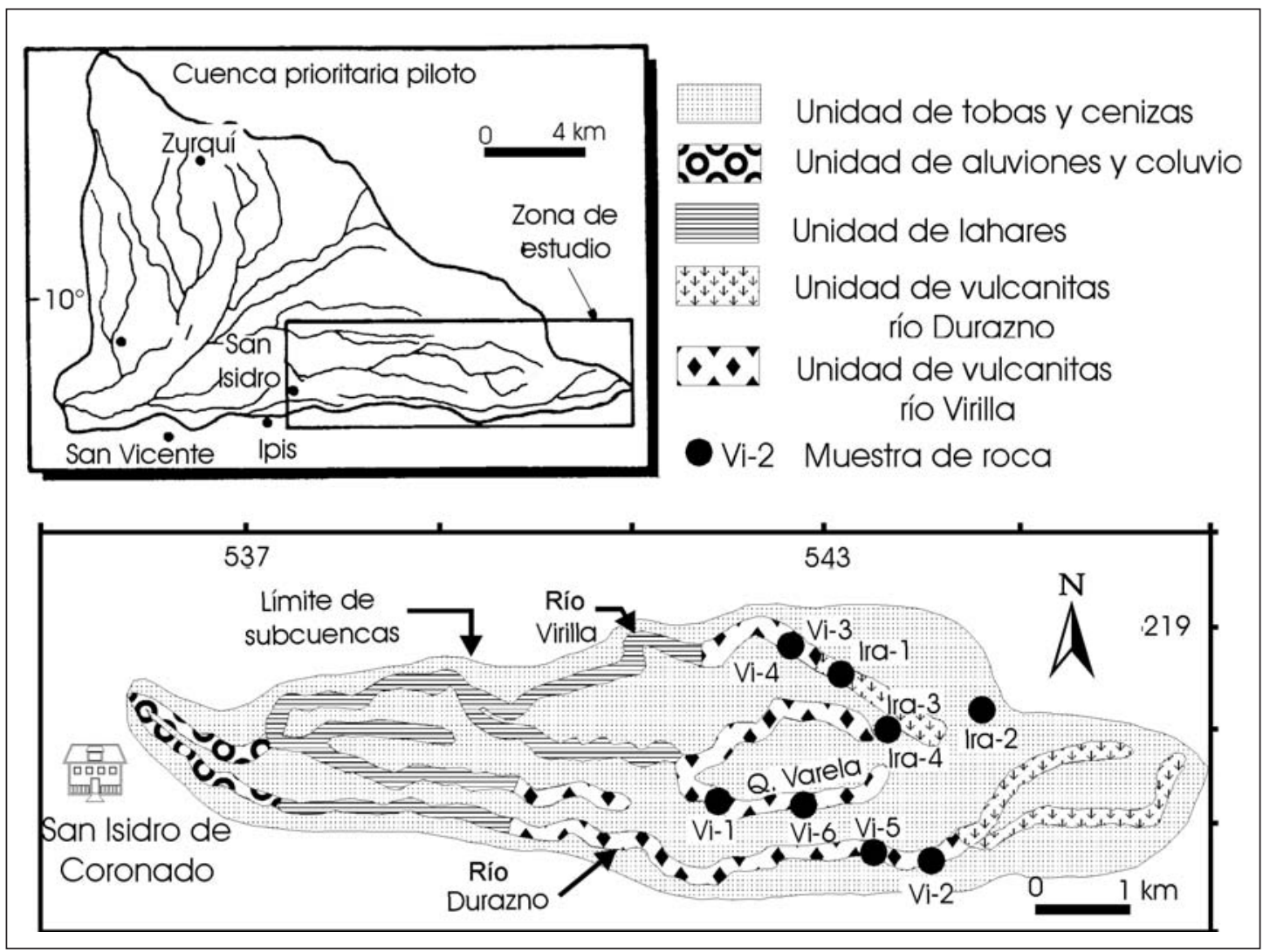

Fig. 2: Mapa geológico esquemático.

Cuadro 1

Características petrográficas de la Unidad lavas del río Virilla (Grupo Aguacate)

\begin{tabular}{|c|c|c|c|c|c|c|c|}
\hline Muestra y & Vi 1 & Vi 2 & Vi 3 & Vi 4 & Vi 5 & Vi 6 & Promedio \\
\hline \multirow[t]{2}{*}{ Coordenadas } & 217,2 & 216,8 & 218,7 & 218,7 & 216,8 & 217,3 & \\
\hline & 542,2 & 544,3 & 542,8 & 542,8 & 543,5 & 542,6 & \\
\hline \multicolumn{8}{|l|}{ Fenocristales } \\
\hline Plagioclasa $(\%)$ & 30,5 & 24,0 & 18,0 & 30,0 & 36,0 & 29,0 & 27,9 \\
\hline Augita titanífera (\%) & 1,5 & 2,5 & 10,0 & 10,0 & 8,0 & 16,5 & 8,1 \\
\hline Olivino $(\%)$ & 6,0 & 4,5 & 3,0 & 4,0 & 4,5 & 2,5 & 4,0 \\
\hline Magnetita (\%) & 2,5 & - & 2,0 & 2,0 & 1,5 & 1,0 & 1,5 \\
\hline Matriz (\%) & 55,5 & 66,5 & 63,0 & 51,0 & 43,0 & 49,5 & 54,8 \\
\hline Vesículas + amigdalas $(\%)$ & 4,0 & 2,5 & 4,0 & 3,0 & 7,0 & 1,5 & 3,7 \\
\hline Nombre de roca & Basalto & Basalto & Basalto & Basalto & Basalto & Basalto & \\
\hline
\end{tabular}

de progresión. Las tobas se observaron solo en el río Virilla en un afloramiento de $1 \mathrm{~m}$ de espesor, de color morado, con $35 \%$ de cristales milimétricos idiomórficos de piroxeno, $35 \%$ de plagioclasa y $30 \%$ de fragmentos de roca. Los lapillis afloran en la quebrada Varela como una capa de $60 \mathrm{~cm}$ de espesor, con componentes escoriáceos de color morado, redondeados, livianos, de tamaño centimétrico y dispuestos con gradación normal.

La figura 4 resume la estratigrafía observada en la quebrada Varela. De lo más antiguo a 


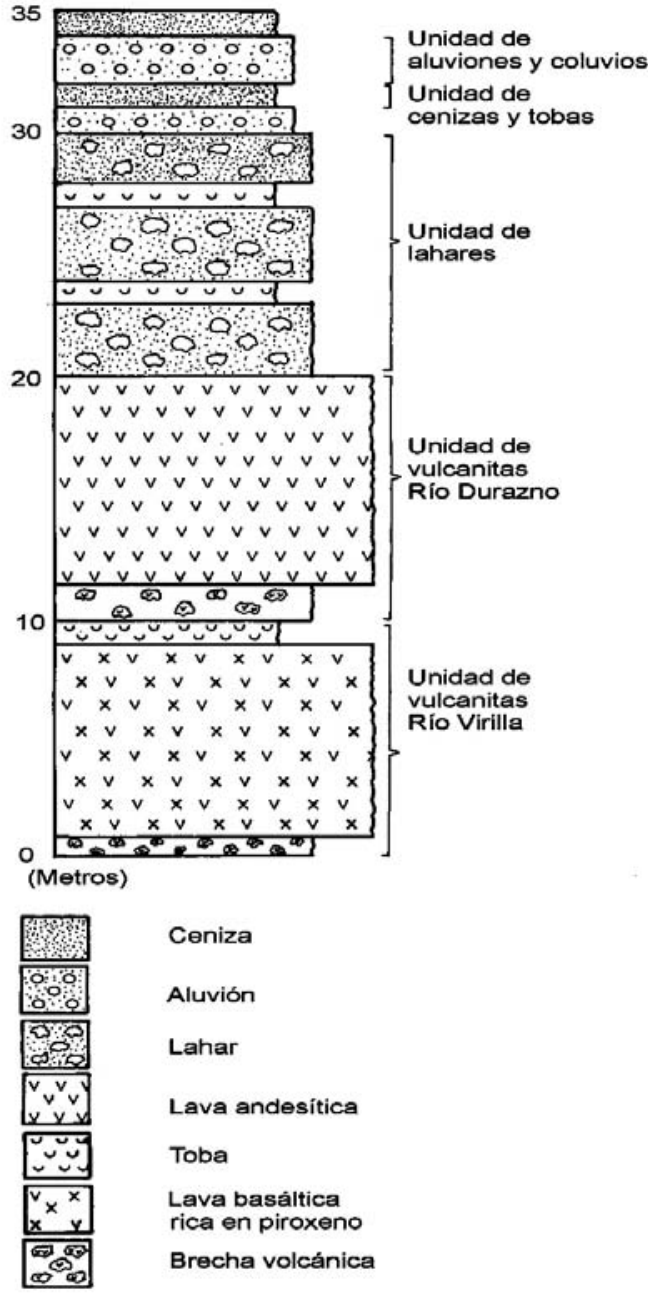

Fig. 3: Columna estratigráfica general.

lo reciente, se presenta una lava basáltica rica en piroxeno de textura porfirítica, brecha de progresión, lava basáltica de textura vesicular, lapilli, cenizas y aluviones, con un espesor total de $22 \mathrm{~m}$. La figura 5 muestra la secuencia litológica en el río Virilla, que consiste de lavas basálticas, lahares, tobas $\mathrm{y}$ aluviones con un espesor total de $10 \mathrm{~m}$.

\section{Unidad de vulcanitas río Durazno}

Esta unidad está compuesta principalmente por lavas y aflora en el río Virilla, el río Durazno a la altura de la Hacienda San Miguel en Rancho Redondo y cerca de la Hacienda Guayabillos.

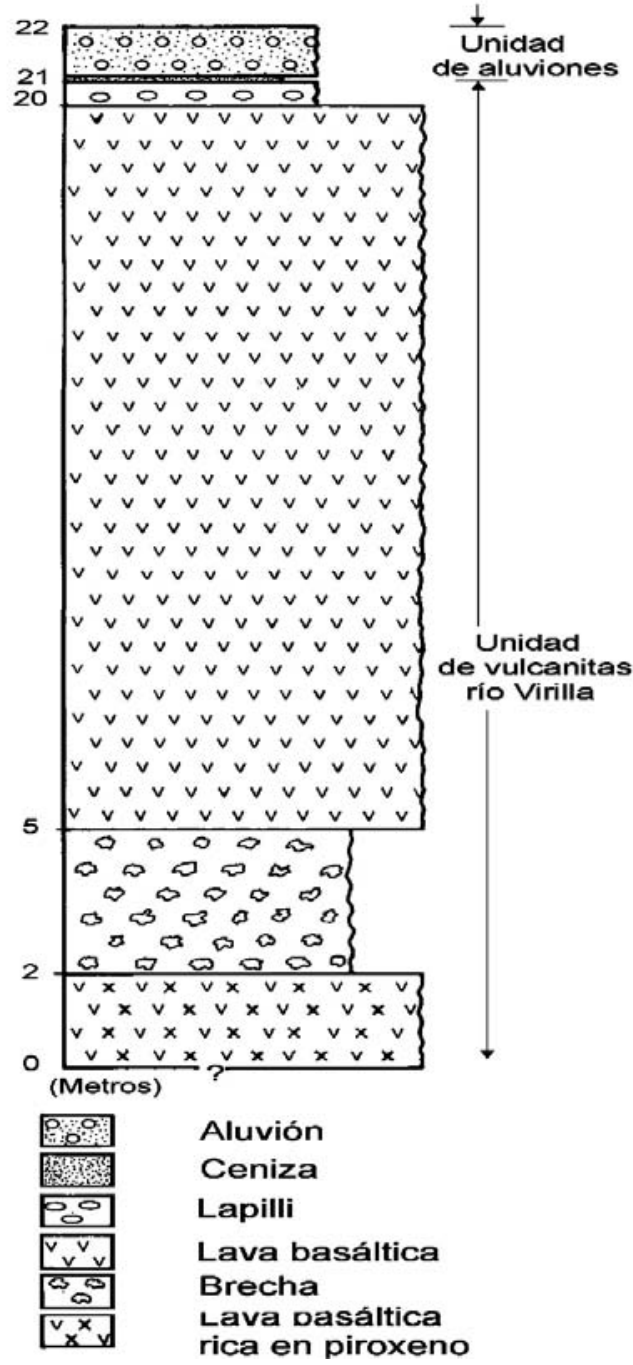

Fig. 4: Columna estratigráfica a partir de afloramientos en la quebrada Varela, coordenadas 542,7-218,2.

El espesor máximo observado es de $10 \mathrm{~m}$. Macroscópicamente está constituida por lavas de color gris claro, de textura porfirítica, con fenocristales idiomórficos de plagioclasa.

Microscópicamente las lavas se clasifican como andesitas porfiríticas, vesiculares, con porcentajes de 24-33\% de fenocristales de plagioclasa, $3-6 \%$ de augita, $1 \%$ de olivino, $1-3 \%$ de hipersteno, $0,5-1,5 \%$ de magnetita y $1-4 \%$ de vesículas. El porcentaje de la mesostasa oscila entre un $56-67 \%$, diferenciándose de las lavas del 

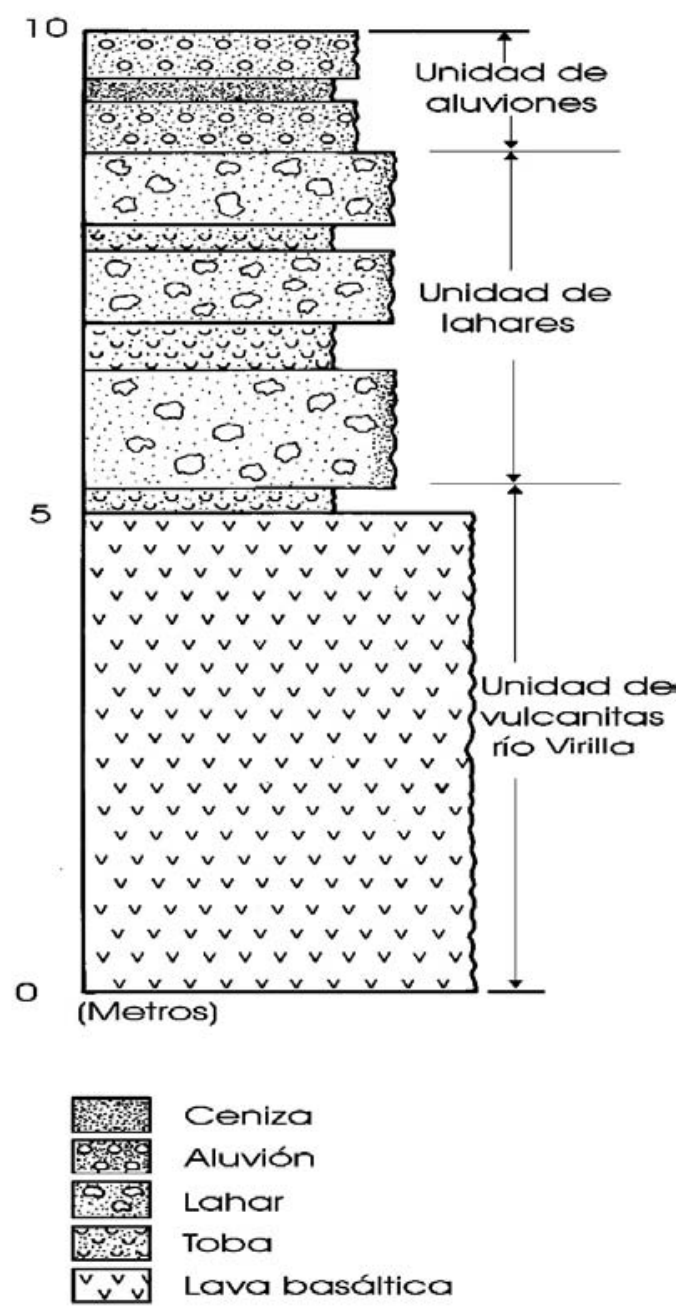

Fig. 5: Columna estratigráfica a partir de afloramientos en la sección alta del río Virilla, coordenadas 542,0-217,6. río Virilla por el porcentaje de mesostasa mayor, un porcentaje menor de piroxenos y la presencia de hipersteno (Cuadro 2).

No se puede afirmar con certeza la edad de los materiales pertenecientes a las unidades río Virilla y río Durazno, sin embargo, petrográficamente se diferencian por el volumen de piroxenos, contenido de hipersteno, y estado de alteración del olivino. Se considera que dos eventos volcánicos separados en el tiempo dieron origen a estas unidades.

Por sus características petrográficas la unidad río Virilla es correlacionable con el Grupo Aguacate (Fm. Grifo Alto), de edad Plioceno, mientras que las lavas del río Durazno son correlacionables con las lavas del Volcán Irazú, asumiéndose una edad Pleistoceno Superior. (Vargas, 1994).

\section{Unidad de Lahares}

Aflora de los 1500 m.s.n.m a los 1850 m.s.n.m a lo largo de la quebrada Montelindo, río Virilla y el río Durazno (Fig. 2). Se presenta como un material heterogéneo y desorganizado, constituido por fragmentos de lava centimétricos, clastos silicificados angulosos y cristales, envueltos en una matriz arcillosa de color amarillo o crema. El espesor máximo observado fue de $5 \mathrm{~m}$. El origen de estos materiales se puede explicar considerando que cerca de los centros de emisión volcánica, se presentan desprendimientos de paredes o depositación de materiales pirocláticos en los cauces de ríos, que ocacionan represamientos de agua en la estación

Cuadro 2

Características petrográficas de la unidad lavas del río Durazno (Irazú)

\begin{tabular}{lccccc}
\hline Muestra y Coordenadas & Ira 1 & Ira 2 & Ira 3 & Ira 4 & Promedio \\
& 218,4 & 218,2 & 218,1 & 543,8 \\
& 543,2 & 544,6 & 543,8 & & \\
Fenocristales & & & & 24,0 & 27,1 \\
Plagioclasa (\%) & 27,0 & 24,5 & 33,0 & 5,5 & 5,1 \\
Augita (\%) & 6,0 & 6,0 & 3,0 & 1,0 & 1,0 \\
Olivino (\%) & 1,0 & 1,0 & 1,0 & 3,0 & 2,0 \\
Hipersteno (\%) & 1,5 & 1,0 & 0,5 & 1,5 & 0,8 \\
Magnetita (\%) & 0,5 & 67,0 & 4,0 & 56,0 & 1,0 \\
Vesículas (\%) & & Andesita & Andesita & Andesita & 63,0 \\
Matriz (\%) & 64,0 & Andesita & & \\
Nombre de la roca & & &
\end{tabular}


lluviosa, susceptibles a generar masas de lodo caliente o frío en movimiento, con una densidad suficiente para arrastrar bloques de diferente tamaño. Estos materiales se intercalan con cenizas (Fig. 6)
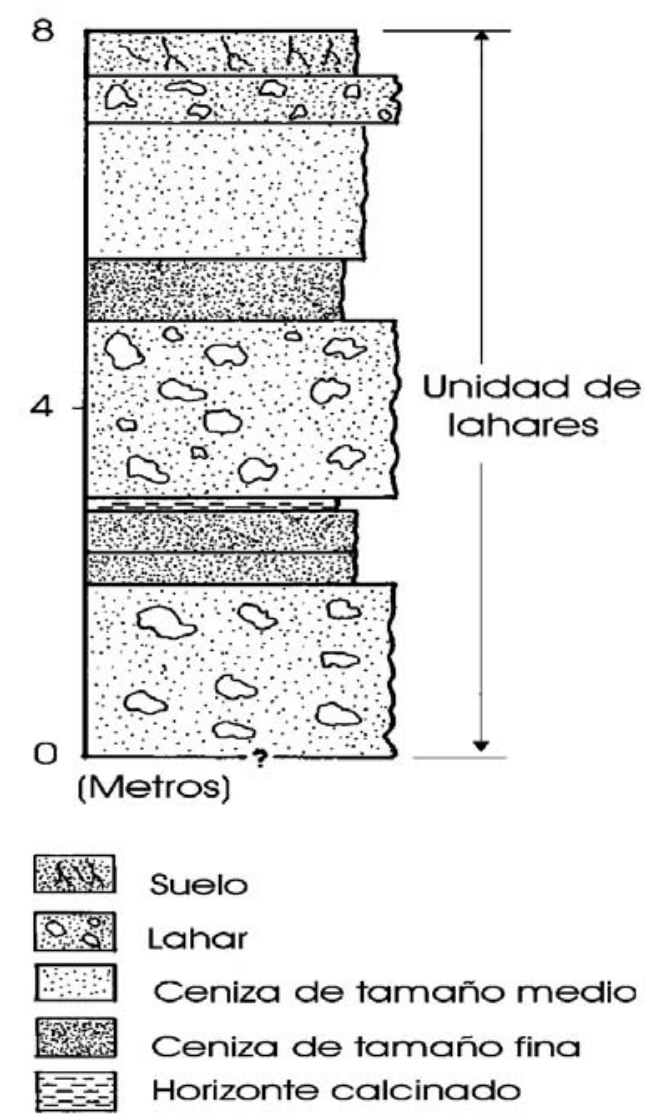

Fig. 6: Columna estratigráfica a partir de afloramientos en la sección baja del río Virilla, coordenadas 536,0-218,2.

y sobreyacen las unidades de lavas. Se consideran de edad Pleistoceno al Reciente por la ocurrencia de eventos similares en otros sitios del Valle Central que han sido asociados a esta edad (Echandi, 1981; Denyer \& Arias, 1991).

\section{Unidad de Aluviones y Coluvios}

Afloran principalmente en los ríos Virilla y Durazno a la altura de San Rafael y San Isidro de Coronado. Están caracterizados por bloques redondeados a semiredondeados de rocas volcánicas, entre ellas, lavas escoriáceas de color rojo a gris oscuro, lavas densas andesíticas porfiríticas y lavas densas de color gris con estructura fluidal. La granulometría varía desde arenas hasta bloques métricos de forma redondeada, ocacionalmente cubiertos por una pátina de óxido de hierro. El espesor máximo alcanza los $10 \mathrm{~m}$, aunque generalmente se presentan en forma de lentes centimétricos a métricos intercalados con capas de ceniza y tobas (Fig. 7). Estos materiales son producto de la meteorización y la erosión fluvial, depositados por el cambio de pendiente topográfica. Sobreyacen a los lahares y lavas, pero se intercalan con los mantos de ceniza, y se consideran de edad reciente. Los
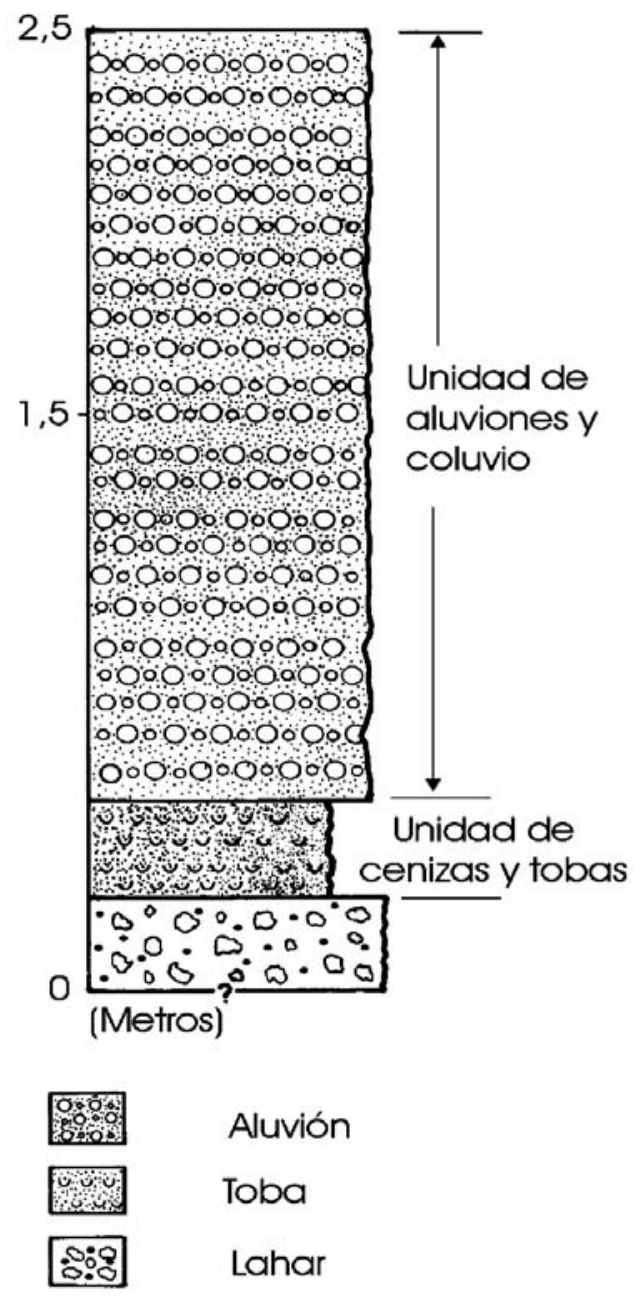

Fig. 7: Columna estratigráfica a partir de afloramientos en la sección baja del río Durazno, coordenadas 536,6-217,0. 
Cuadro 3

Análisis numérico morfológico de las subcuencas Virilla - Durazno

Parámetro
Área $\left(\mathrm{km}^{2}\right)$
Perímetro $(\mathrm{km})$
Longitud axial $(\mathrm{km})$
Ancho promedio $(\mathrm{km})$
Long. Canales $(\mathrm{km})$
No de canales $(\mathrm{canales})$
Densidad Canal $\left(\mathrm{can} / \mathrm{km}^{2}\right)$
Densidad Drenaje $\left(\mathrm{km} / \mathrm{km}^{2}\right)$

Parámetro

Ancho promedio $(\mathrm{km})$

Densidad Drenaje $\left(\mathrm{km} / \mathrm{km}^{2}\right)$

\section{Subcuenca río Virilla}

9,97

20,42

9,21

1,10

54,21

101

10,13

5,43
Subcuenca río Durazno

8,7

25,6

11,6

0,8

34,4

69

7,9

4,0 coluvios son menos frecuentes que los aluviones y se caracterizan por bloques de lava de composición similar a los aluviones, pero englobados en una matriz arcillosa y originados como desprendimientos de taludes y acumulaciones de pie de monte. Los aluviones son explotados comercialmente por medio de tajos, en forma de "piedra bruta" (bloques con diámetros mayores de $20 \mathrm{~cm}$ ), como "piedra quebrada" o como "arena de río". Se prefieren los bloques de lava andesítica por su resistencia y durabilidad en la construcción.

\section{Unidad de Tobas y Cenizas Recientes}

Las cenizas cubren los materiales ya citados, por lo que en la figura 2, se han colocado sobre todo el mapa, excepto en aquellos sectores donde la erosión fluvial permite el afloramiento de otros materiales. Es común observar las capas de ceniza en los cortes de caminos a Los Alpes y Patio de Agua. Las tobas por su parte aparecen en cortes del río Virilla en San Rafael y el río Durazno en San Francisco. Están constituidas por cristales, fragmentos de roca y vidrio volcánico, en tamaños que varían de 0,4 hasta $0,1 \mathrm{~mm}$. El color de la ceniza meteorizada es gris y para la ceniza sana es azulado, y el color de las tobas varía de gris a rojo. Estos materiales proceden de las erupciones periódicas de piroclastos que ha hecho el volcán Irazú, lográndose diferenciar a partir de afloramientos hasta cuatro emisiones con cambios en la granulometría separados por flujos laháricos.

\section{GEOMORFOMETRÍA}

La definición de las formas del terreno se ha hecho considerando las subcuencas de los ríos Virilla y Durazno, las cuales están modeladas por la litología, las estructuras volcano-tectónicas locales, la red de drenaje, los procesos erosivos y factores antrópicos. Para cada subcuenca se han estimado características morfométricas (Cuadro 3), definidas por Wisler \& Brater (1959); Mijares (1989); Linsley et al.,(1992). La subcuenca del río Virilla tiene un área mayor $\left(9,97 \mathrm{~km}^{2}\right)$, un perímetro menor $(20,4 \mathrm{~km})$ una longitud de canales mayor $(54,2 \mathrm{~km})$ y más cantidad de canales (101). Esto permite señalar que la subcuenca está mejor drenada, es más achatada, presenta un estado de desarrollo juvenil y un mayor número de canales por kilómetro cuadrado (10,13 can./km²). Es decir, aún cuando recoge más precipitación, esta se distribuye inicialmente en los canales y no en el río principal, pero el recorrido del río Virilla hasta la salida de la cuenca es menor.

La subcuenca del río Durazno, presenta un área menor $\left(8,7 \mathrm{~km}^{2}\right)$, un perímetro mayor $(25,58$ $\mathrm{km})$, que se explica por la longitud axial mayor $(11,6 \mathrm{~km})$. Además el promedio del ancho es de $0,8 \mathrm{~km}$, con 69 canales y una longitud de canales de $34,4 \mathrm{~km}$. Esto implica que esta subcuenca es más estrecha, pero a la vez más elongada permitiendo la rápida concentración de agua en el cauce principal, sin embargo el recorrido hasta la salida de la cuenca es mayor. 
Cuadro 4

Análisis de órdenes en las subcuencas Virilla-Durazno

\begin{tabular}{|c|c|c|c|c|c|c|}
\hline \multirow[t]{2}{*}{ Orden } & \multicolumn{2}{|c|}{ No. Corrientes } & \multicolumn{2}{|c|}{ Razón bifurcación } & \multicolumn{2}{|c|}{$\begin{array}{c}\text { Razón bifurcación } \\
\text { Promedio }\end{array}$} \\
\hline & Virilla & Durazno & Virilla & Durazno & Virilla & Durazno \\
\hline 1 & 83 & 58 & 6,9 & 6,4 & 6,6 & 6,3 \\
\hline 2 & 12 & 9 & 3,0 & 9,0 & 0,5 & 1,3 \\
\hline 3 & 4 & 1 & 4,0 & 1,0 & 0,2 & 0,03 \\
\hline 4 & 1 & 1 & 1,0 & & 0,02 & \\
\hline 5 & 1 & & & & & \\
\hline
\end{tabular}

Además, la densidad de canales es de 7,9 canales $/ \mathrm{km}^{2}$ y la densidad de drenaje es de 4,0 $\mathrm{km} / \mathrm{km}^{2}$, ratificando la existencia de un colector principal con pocos canales secundarios. Esto es confirmado aún más al observar el cuadro 4, referente al orden de los canales. En la subcuenca del río Virilla existen 83 canales de orden 1 y el canal principal es de orden 5, mientras que en la subcuenca del río Durazno, hay solamente 58 canales y el canal principal tiene un orden 4. Por su parte los perfiles longitudinales muestran para el río Virilla y el río Durazno (Fig. 8), una pendiente de $83,3 \mathrm{~m} / \mathrm{km}$ y de $66,6 \mathrm{~m} / \mathrm{km}$ respectivamente. Por otro lado, a partir de las curvas hipsométricas (Fig. 9), se aprecia uniformidad de pendiente para los dos ríos, es decir el porcentaje de área está distribuida proporcionalmente. Además, se observa que el 50\% del área de drenaje se encuentra entre 2000 y 2500 m.s.n.m, para la subcuenca del río Virilla y entre 2000 y 2800 m.s.n.m, para la subcuenca del río Durazno.

\section{UNIDADES GEOMÓRFICAS}

Dentro de las subcuencas se han definido seis unidades; unidad de pendiente muy alta, unidad de pendiente alta, unidad de gargantas y barrancos, unidad de pendiente moderada, unidad de transición y unidad de pendiente baja (Fig. 10).
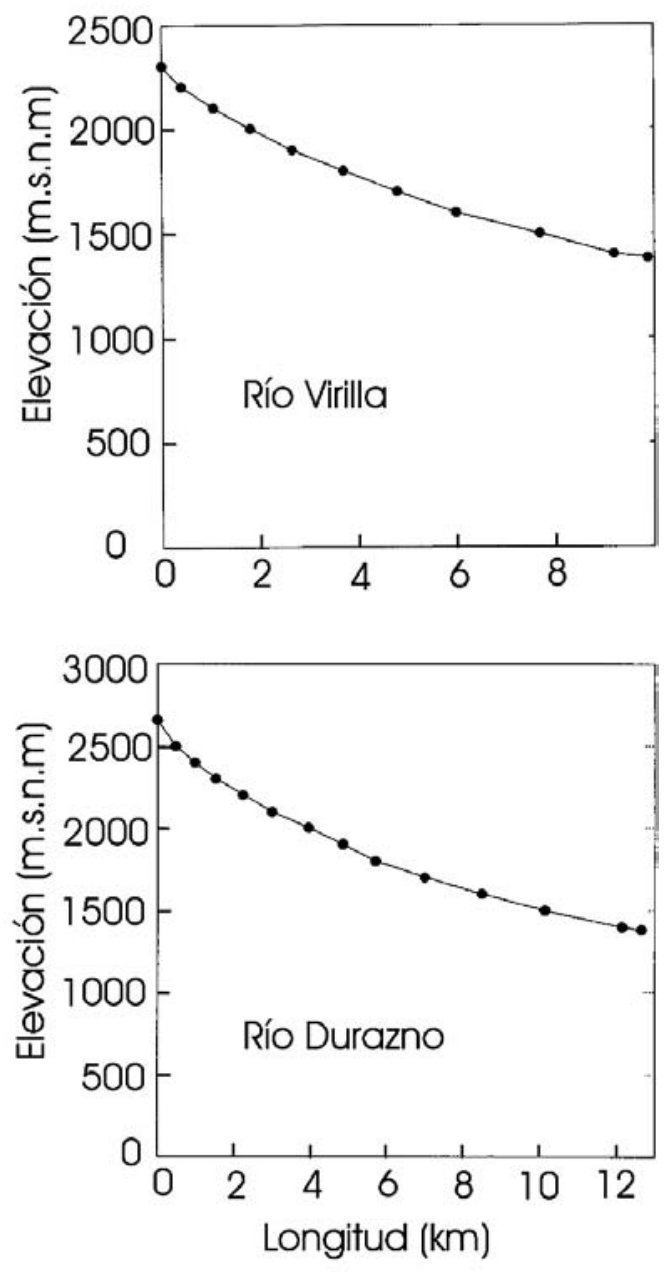

Fig. 8: Perfiles longitudinales del río Virilla y del río Durazno. 


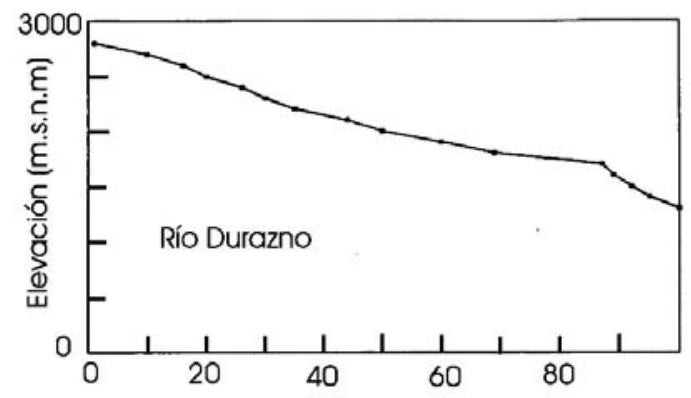

\section{Unidad de pendiente muy alta}

Se ubica al Este en las subcuencas de estudio y ocupa $2,7 \mathrm{~km}^{2}$ (Cuadro 4). Las pendientes del terreno varían de $35-55^{\circ}$, la densidad de drenaje de $2700-4200 \mathrm{~m} / \mathrm{km}^{2}$ y el relieve relativo de $300-420 \mathrm{~m} / \mathrm{km}^{2}$. La base de la unidad está a 2100 m.s.n.m y se eleva hasta 2660 m.s.n.m en la cumbre del Cerro Pico de Piedra, el patrón de drenaje es subdendrítico (Fig. 10).

Esta unidad tiene una orientación E-W, se

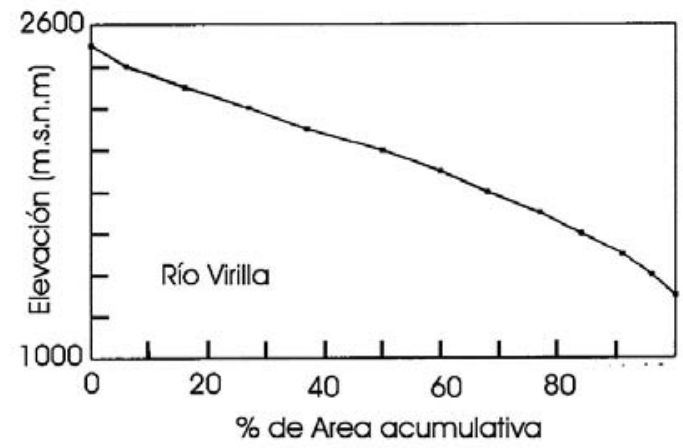

Fig. 9: Curvas hipsométricas del río Durazno y del río Virilla. caracteriza por una estructura volcánica (cono adventicio o cráter) erosionada, con la pared Oeste desprendida y cuyos materiales se depositaron cerca de la localidad de las Nubes. El cráter presenta una terraza en el flanco Norte y tiene su culminación en el Cerro Pico de Piedra, actualmente cubierto de vegetación. En el interior de dicha estructura nace el río Virilla a la altura de 2300 m.s.n.m. Está constituida por lavas basálticas y andesíticas y piroclastos. Esta unidad se originó probablemente en el Plioceno tal como se ha propuesto para la unidad geológica río Virilla.
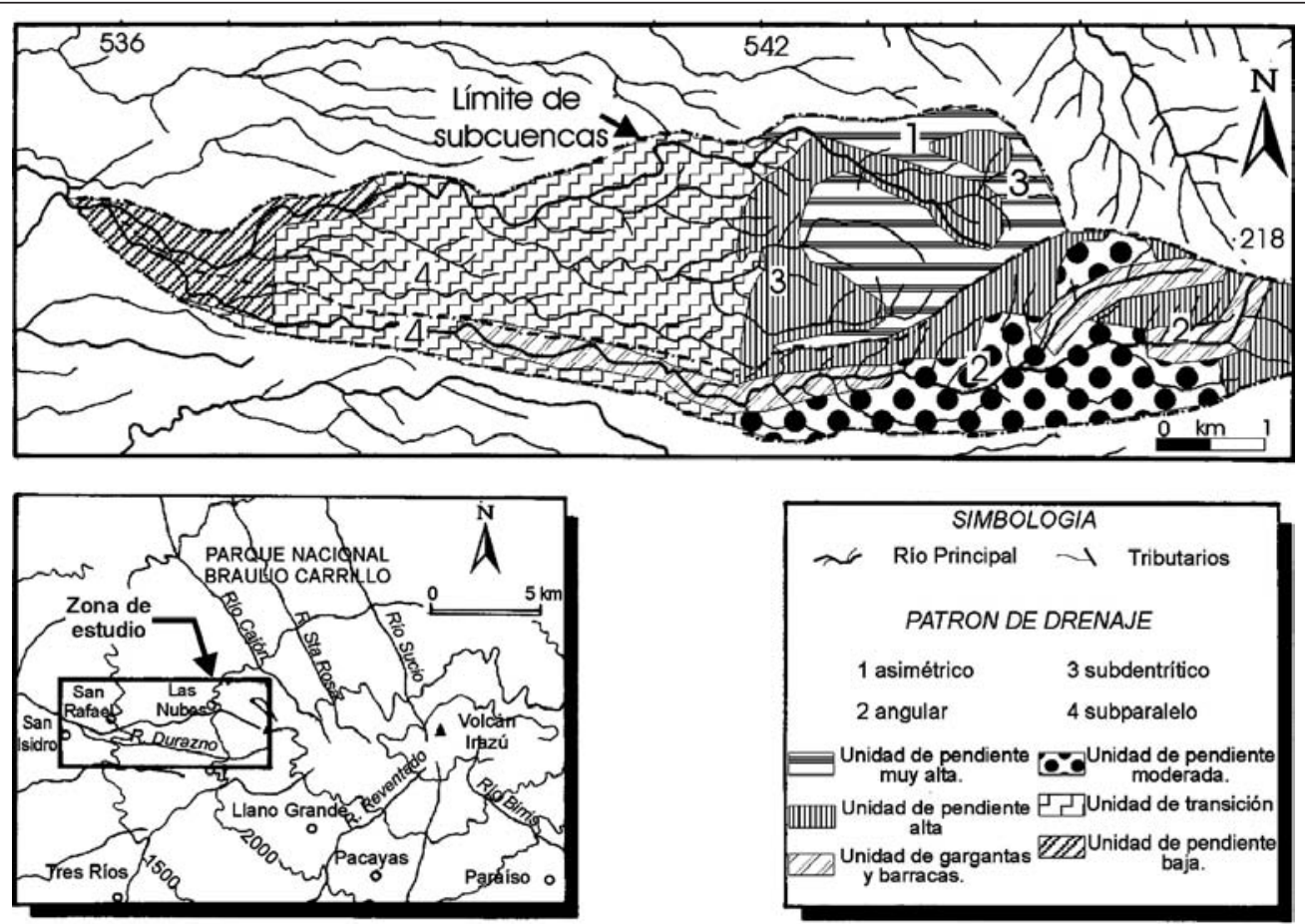

Fig. 10: Mapa de unidades geomórficas y red de drenaje. 
Cuadro 5

Área de las unidades geomórficas en las subcuencas Virilla-Durazno

\begin{tabular}{lcc}
\hline Unidad & $\%$ Área & Área $\left(\mathrm{km}^{2}\right)$ \\
Pendiente muy alta & 14,3 & 2,7 \\
Pendiente alta & 23,9 & 4,5 \\
Gargantas y barrancos & 5,4 & 1,0 \\
Pendiente moderada & 15,5 & 2,9 \\
Transición & 33,2 & 6,2 \\
Baja & 7,7 & 1,4 \\
Total & 100,0 & 18,7 \\
\hline
\end{tabular}

\section{Unidad de pendiente alta}

Se ubica al Este en la zona de estudio en las localidades denominadas Chino, Conde, Hacienda San Fernando y parte de la Hacienda Abigail. La unidad abarca $4,5 \mathrm{~km}^{2}$ de las subcuencas. Las pendientes del terreno oscilan entre $15-35^{\circ}$, la densidad de drenaje varía de 2600 $5000 \mathrm{~m} / \mathrm{km}^{2}$ y el relieve relativo oscila de 180 $400 \mathrm{~m} / \mathrm{km}^{2}$. La altura mínima corresponde a 1900 m.s.n.m y la mayor a 2900 m.s.n.m, cerca de Chino. La red de drenaje es de tipo subdendrítico y angular. Corresponde con las nacientes del río Durazno. Las divisorias son agudas, con ángulos de $35^{\circ}$. Las laderas son planas a convexas. Es frecuente la reptación superficial en los terrenos desprotegidos, ocacionalmente se presentan deslizamientos pequeños. El límite Oeste de la unidad se caracteriza por laderas de fuerte pendiente que se interpretan como un frente de colada de lava, de forma convexa. La litología de esta unidad está constituida por lavas basálticas y andesíticas y se formó posiblemente como producto de la actividad del Grupo Aguacate, y luego por influencia de la emisión de materiales en conos adventicios del Irazú en el Pleistoceno.

\section{Unidad de gargantas y barrancos fluviales}

Se presenta en el río Durazno en las secciones superiores y medias. Abarca $1,0 \mathrm{~km}^{2} \mathrm{del}$ área de las subcuencas. La inclinación de las paredes varía de $25-45^{\circ}$ y el relieve relativo oscila entre 160 y $360 \mathrm{~m} / \mathrm{km}^{2}$. Estas gargantas y barrancos son sectores estrechos del cauce del río, labradas por el discurrir contínuo del agua, cuyo ancho oscila entre 5-50 m y 50- $200 \mathrm{~m}$, y la profundidad entre $0-10 \mathrm{~m}$ y $10-50 \mathrm{~m}$ respectivamente. La longitud acumulativa de las secciones de esta unidad suman $6,8 \mathrm{~km}$. La erosión fluvial ha modelado las lavas posiblemente desde el Plioceno, época en la cual dichos materiales fueron emitidos y expuestos a la acción fluvial.

\section{Unidad de pendiente moderada}

Se localiza al E del área, en las haciendas San Miguel y Guayabillos. Comprende 2,9 km² de las subcuencas. Las pendientes del terreno oscilan de $4-27^{\circ}$. Las elevaciones del terreno varían de 1940 hasta 2540 m.s.n.m. El patrón de drenaje es angular. Está caracterizada por una depresión orientada E-W, rodeada por dos escarpes, a manera de graben. Está atravezada por el río Durazno de manera lineal. Las pequeñas lagunas son frecuentes y la reptación es moderada. La litología se compone de lavas basálticas y andesíticas y cenizas. En cuanto a la morfogénesis, se trata posiblemente de un deslizamiento antiguo, cuyos materiales se depositaron cerca de Rancho Redondo.

\section{Unidad de transición}

Se localiza en Patio de Agua, Finca Monte Lindo, Finca Santa Teresita y Finca Cabaña. $\mathrm{Su}$ área es la más extensa entre las unidades con $6,2 \mathrm{~km}^{2}$. La pendiente varía de $5-21^{\circ}$. La base de la unidad se encuentra a 1500 m.s.n.m, definida por el cambio de pendiente, hasta 1980 m.s.n.m. El patrón de drenaje es subparalelo, definido por las quebradas Montelindo, Varela y el río Durazno. El río Virilla por su parte se muestra sinuoso. Son comunes los deslizamientos de pequeña envergadura $\left(300 \mathrm{~m}^{2}\right)$.

Los materiales aluvionales, cenizas, y lahares forman esta unidad y afloran en los ríos principalmente. Se considera que la erosión de la estructura volcánica Las Nubes, definida en la unidad de pendiente muy alta, ha permitido la generación de aluviones y lahares que han sido cubiertos por cenizas provenientes del volcán Irazú. Estos materiales han dado lugar a un sector sin cambios topográficos abruptos, permitiendo el discurrir paralelo de 
las aguas. Este modelado se ha dado posterior al emplazamiento del paleovolcán Las Nubes, por lo que se estima para esta unidad una edad de Pleistoceno al Reciente.

\section{Unidad de pendiente baja}

Se localiza cerca de la localidad de San Rafael y San Isidro. La extensión areal es de 1,4 $\mathrm{km}^{2}$. Presenta pendientes bajas de $5-12^{\circ}$, una densidad de drenaje de $3000-4100 \mathrm{~m} / \mathrm{km}^{2}$, un relieve relativo de $60-80 \mathrm{~m} / \mathrm{km}^{2}$ y un patrón de drenaje subparalelo. En esta unidad afloran cenizas, lahares y aluviones intercalados en las márgenes de los ríos Virilla y Durazno. Su edad es Pleistoceno Superior al Reciente.

\section{FORTALECIMIENTO DEL PLAN REGULADOR}

Dentro del plan regulador del Cantón Vázquez de Coronado (Unidad Técnica, 1996), se establecen tres proyectos en los cuales se deberían tomar en cuenta la componente geoambiental involucrando la geología, geomorfología e hidrogeología entre otras. Estos tres proyectos son el fortalecimiento de la actividad agropecuaria cantonal, el proyecto del paradero turístico y la ubicación de un relleno sanitario.

Para la ubicación de un relleno sanitario la Unidad Técnica de la Municipalidad Vázquez de Coronado ha propuesto una metodología basada en seis puntos principales (Cuadro 6). Entre estos

Cuadro 6

Valoración de parámetros para elección de sitios para rellenos sanitarios

\begin{tabular}{lc}
\hline Parámetros & Valores (puntos) \\
Drenaje y contaminación & 25 \\
Crecimiento urbano & 25 \\
Accesibilidad & 20 \\
Características geológicas y geomórficas & 15 \\
Extensión del terreno & 10 \\
Uso actual y vegetación & 5 \\
\hline
\end{tabular}

Fuente: Unidad técnica, Municipalidad Vázquez de Coronado, 1996. se considera como aspectos de mucha importancia al drenaje así como el crecimiento urbano. Sin embargo no se toman en cuenta aspectos como geología, geomorfología, amenazas naturales, clima y zonas de recarga.

Por lo tanto, para fortalecer el plan regulador del cantón de Coronado se deberían considerar aspectos sobre la geomorfología ya que dentro del área de estudio (Cuencas Virilla-Durazno) dominan las pendientes en condición de moderada hasta muy alta y una precipitación promedio mensual que varía desde 22 hasta $374 \mathrm{~mm}$ lo que significa desde 220 hasta $374 \mathrm{~m}^{3} / \mathrm{ha}$, que favorece la escorrentía superficial. Tanto la ubicación de un relleno sanitario como la construcción de urbanizaciones se podrían realizar en las zonas de las unidades de pendiente baja y de transición, evitando la construcción en las unidades de pendiente muy alta, alta y de gargantas y barrancas. Sin embargo, es necesario que en cada caso se realicen estudios más detallados y los respectivos estudios de impacto ambiental. El proyecto de fortalecimiento de la actividad agrícola debe incluir prácticas adecuadas de conservación de suelos y del recurso hídrico, sobre todo en sectores donde las pendientes dominantes son elevadas.

\section{CONCLUSIONES}

Las rocas presentes en las subcuencas parte alta del río Virilla y del río Durazno son principalmente de tipo volcánico. Las vulcanitas de la unidad del río Virilla se originaron en centros de emisión asociados posiblemente al Grupo Aguacate mientras que las vulcanitas de la unidad río Durazno en centros de emisión relacionados con el Volcán Irazú. El origen de los lahares se asocia a las laderas del paleovolcán Las Nubes o al Cerro Cabeza de Vaca, mientras que las capas de ceniza provienen de la actividad reciente en el volcán Irazú.

La forma de las subcuencas, las estructuras volcánicas locales, la red de drenaje, los procesos erosivos y el modelado antrópico definen dimensiones morfológicas propias para cada subcuenca estudiada. 
La unidad geomorfológica de transición es con $6,2 \mathrm{~km}^{2}$ la más extensa, y sus características deben tomarse en cuenta en el momento de diseñar un plan regulador dentro del cual se contemple la construcción de urbanizaciones en esta unidad.

La construcción de urbanizaciones u obras civiles en esta unidad debe ser restringida, pues las pendientes son pronunciadas, los cauces son estrechos y profundos, permitiendo la evacuación de grandes cantidades de agua en poco tiempo.

Los estudios geológicos y geomorfológicos, combinados con información sobre el uso del suelo, brindan resultados muy valiosos para el manejo de cuencas que puede ser llevado a cabo más efectivamente usando sistemas de información geográfica y se deben incluir en todo plan regulador que se pretenda desarrollar.

\section{REFERENCIAS}

DENYER P. \& ARIAS O., 1990: Geología de la hoja Abra .- Mapa escala 1:50 000, I.G.N., San José.

DENYER, P. \& ARIAS, O., 1991: Estratigrafía de la región central de Costa Rica.- Rev. Geol. Amér. Central, 12: 1-59, San José.

DENYER, P; KUSSMAUL, S. \& ARIAS, O., 1994: Estratigrafía de las rocas ígneas. - En: DENYER, P. \& KUSSMAUL, S. (eds.): Atlas geológico de la Gran Área Metropolitana. - Editorial Tecnológica, Cartago: 61-70.

ECHANDI, E., 1981: Unidades volcánicas de la vertiente Norte de la cuenca del río Virilla.123 págs. Univ. de Costa Rica, San José [Tesis Lic.].

KUSSMAUL, S., 1994: Petrología de rocas ígneas: Mineralogía, geoquímica y génesis de magmas. - En: DENYER, P. \& KUSSMAUL, S. (eds.): Atlas geológico de la
Gran Área Metropolitana. - Editorial Tecnológica, Cartago.: 71-88.

KUSSMAUL, S. \& SPRECHMANN, P., 1984: Unidades litoestratigráficas ígneas. - En: SPRECHAMNN, P. (ed.): Manual de Geología de Costa Rica. Volumen 1: Estratigrafía. - Editorial UCR, San José: 291-300.

KRUSHENSKY, D.,1972 : Geology of the Istarú Quadrangle, Costa Rica. - Geol. Surv. Bull. 1358:1-46.

LINSLEY, R. KOHLER, M. \& PAULHUS, J., 1992: Hidrology for engineers. - 386 págs. Mc Graw Hill, New York.

MIJARES, A. 1989: Fundamentos de hidrología de superficie. - 450 págs. Limusa, México.

TOURNON, J., 1983: La cadena volcánica cuaternaria de Costa Rica: composiciones químicas de las lavas, presencia de dos tipos de series. - Inf. Sem. Inst. Geogr.Nac. 2: 3-62, San José.

WISLER, C. \& BRATER, E., 1959: Hydrology [2a ed.]. - 408 págs. Wiley, New York.

VARGAS, A., 1994: Evaluación de características químicas de aguas superficiales e hidrogeológicas en las subcuencas parte alta río Virilla y río Durazno, Cantón Vázquez de Coronado. - 209 págs. Univ. de Costa Rica, San José [Tesis Lic.]

UNIDAD TÉCNICA PROYECTO PLAN REGULADOR., 1996: Hacia una planificación estratégica: propuestas de desarrollo de corto, mediano y largo plazo.- 66 págs. Municipalidad Vázquez de Coronado, Coronado [Informe interno]. 